\title{
Vielen Dank!
}

Der 50. Jahrgang der Phlebologie ist mit dem vorliegenden Heft abgeschlossen. Wir möchten uns bei allen bedanken, die unsere Zeitschrift gelesen oder an ihren fachlichen Inhalten mitgewirkt haben: Herzlichen Dank für Ihr Interesse, für Ihr Engagement und Ihr Vertrauen!

Besonders danken wir unseren Gastschriftleitern für ihr tatkräftiges Engagement:

Gabriele Faerber

Houman Jalaie

Erika Mendoza

Anya Miller

Dominic Mühlberger

Knuth Rass
Ebenfalls ein ganz besonderer Dank gilt all jenen, die uns bei den zahlreichen Begutachtungsverfahren oder bei der Akquise der Artikel unterstützt haben und auf deren Expertise und große Sorgfalt wir uns jederzeit verlassen konnten - namentlich sind dies:

Guido Bruning

Horst Gerlach

Karsten Hartmann

Tobias Hirsch

Hanno v. Koschitzky

Werner Lang

Erika Mendoza

Stefanie Reich-Schupke

Markus Stücker

Jasmin Woitalla-Bruning

Ganz gleich, ob Sie der Phlebologie nun lesend, schreibend, mit Ihrer Begutachtungskompetenz oder ganz einfach in Freundschaft verbunden sind: Wir wünschen Ihnen allen ein glückliches und gesundes neues Jahr!

Schriftleitung und Verlag 